\title{
Suppurative cholangitis induced by a fully covered self-expandable metal stent covering cystic stumps in a post-liver transplant patient
}
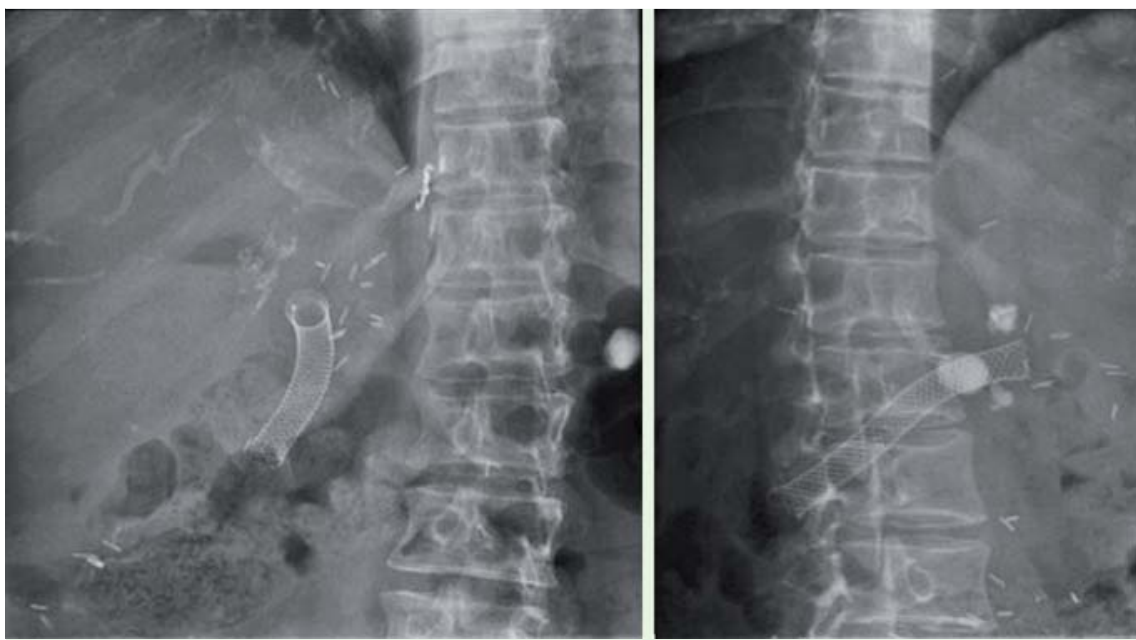

Fig. 1 Abdominal plain film showing the fully covered self-expandable metal stent in place.

A 34-year-old woman presented with hepatalgia, fever, and chills. She had previously undergone three successive liver grafts. Most recently, she had developed a symptomatic biliary anastomotic stricture, which was treated by placement of plastic stents. Three weeks before her admission, she was treated for cholangitis related to the distal migration of the plastic stents. A $10-\mathrm{mm}$ diameter $\times 80-\mathrm{mm}$ long fully covered self-expandable metal stent (Fc-SEMS) (Wallflex; Boston Scientific, Natick, Massachusetts, USA) was placed across the stricture, with the expectation of good results [1].

On admission, physical examination revealed slightly painful liver and fever $\left(38.5^{\circ} \mathrm{C}\right)$. Blood tests showed isolated mild cholestasis and low C-reactive protein (CRP) level $(19 \mathrm{mg} / \mathrm{L})$. Intravenous antibiotic treatment was initiated. Abdominal plain film ( $\bullet$ Fig.1) and magnetic resonance cholangiopancreatography ( $\bullet$ Fig. 2) showed no stent migration or intrahepatic biliary tract dilatation, but there was suspicion of intraprosthetic sludge. CRP increased to $180 \mathrm{mg} / \mathrm{L}$ and blood cultures were positive for Escherichia coli.

The cholangiogram confirmed the adequate transpapillary and subhilar position of the stent and normal intrahepatic bile ducts ( Fig.3a). Pulling on the inflated balloon in the stent did not disclose any material but did lead to stent dislodgement under the stricture, revealing two cystic duct remnants ( Fig.3b). Simultaneously, pus was flowing through the stent and the duodenum. The Fc-SEMS was replaced by three plastic stents across the stricture. The patient was discharged 3 days later with oral antibiotics. At follow-up 2 months later, the plastic stents were still in place and the patient was asymptomatic.

As far as we know, this cause of cholangitis has never been described and is probably related to the specific anatomy of this transplant patient, with the stricture close to two cystic stumps. Similarly, the incidence of cholecystitis associated with Fc-SEMS placement has been reported as negligible $[2,3]$. The use of Fc-SEMS for post-transplant biliary stenosis treatment is controversial, may be associated with more complications, and should only be used in highly specialized, tertiary referral centers $[4,5]$.

Endoscopy_UCTN_Code_CPL_1AK_2AD

Competing interests: None
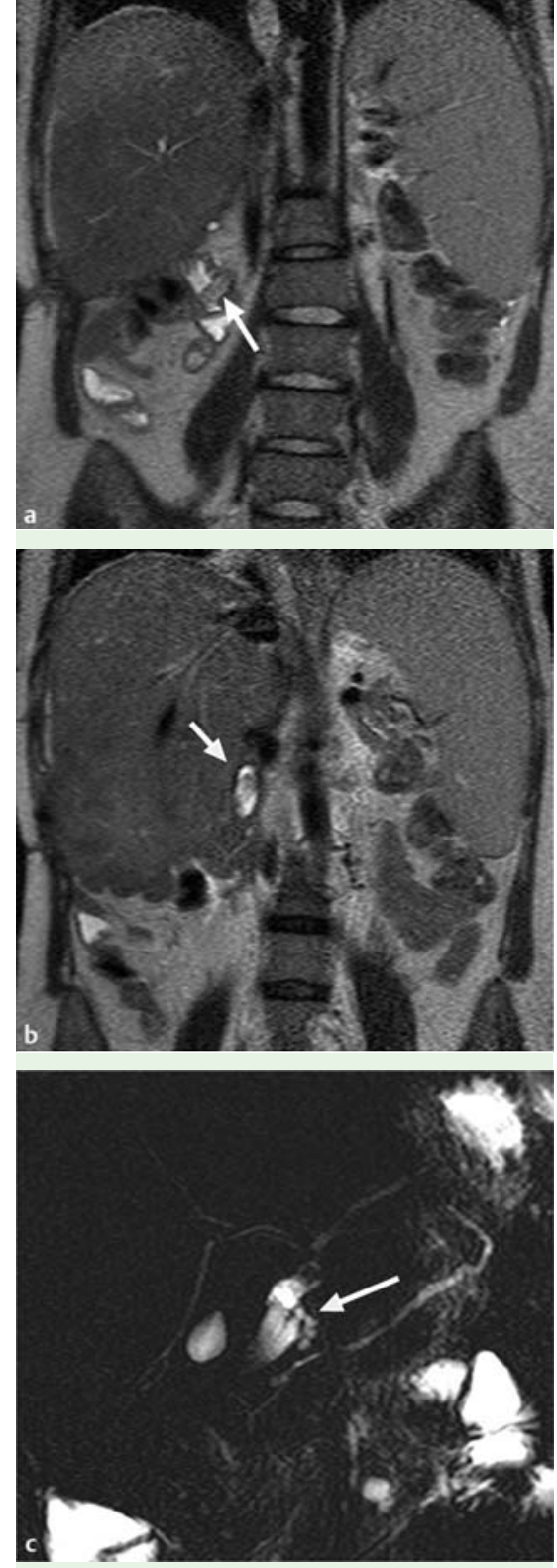

Fig. 2 Magnetic resonance cholangiopancreatography. a, b Absence of intrahepatic biliary duct dilatation, but suspicion of sludge in the stent. c Dilatation of the cystic stump. 

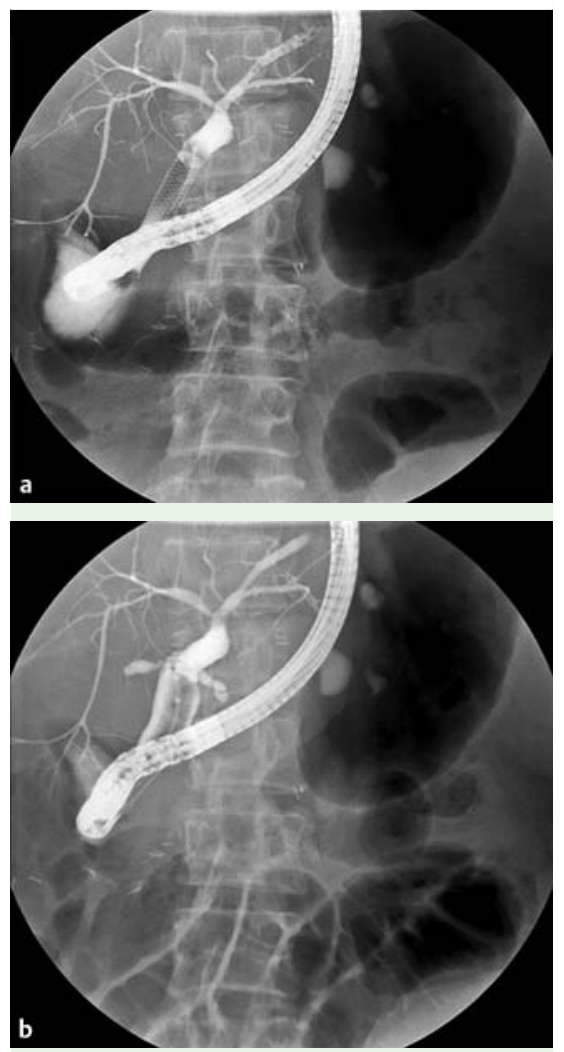

Fig. 3 Cholangiogram. a Stent in place: there was neither intrahepatic bile duct dilatation nor bile material inside the stent. $\mathbf{b}$ The stent was dislodged revealing the two cystic stumps at the level of the anastomotic stricture.
Arnaud Lemmers ${ }^{1}$, Vincent Huberty ${ }^{1}$,

Delphine Degré ${ }^{1}$, Celso Matos ${ }^{2}$, Olivier Le Moine ${ }^{1}$, Jacques Devière ${ }^{1}$

${ }^{1}$ Department of Gastroenterology, Hepatopancreatology, and Digestive Oncology, Erasme Hospital, Université Libre de Bruxelles, Brussels, Belgium

2 Department of Radiology, Erasme Hospital, Université Libre de Bruxelles, Brussels, Belgium

\section{References}

1 Hu B, Gao DJ, Yu FH et al. Endoscopic stenting for post-transplant biliary stricture: usefulness of a novel removable covered metal stent. J Hepatobiliary Pancreat Sci 2011; 18: 640-645

2 Poley JW, Cahen D, Metselaar HJ et al. A prospective group sequential study evaluating a new type of fully covered self-expandable metal stent for the treatment of benign biliary strictures. Gastrointest Endosc 2012; 75: $783-789$

3 Tarantino I, Mangiavillano B, Di Mitri R et al. Fully covered self-expandable metallic stents in benign biliary strictures: a multicenter study on efficacy and safety. Endoscopy 2012; 44: 923-927
4 Tarantino I, Traina M, Mocciaro F et al. Fully covered metallic stents in biliary stenosis after orthotopic liver transplantation. Endoscopy 2012; 44: 246-250

5 Phillips MS, Bonatti H, Sauer BG et al. Elevated stricture rate following the use of fully covered self-expandable metal stents for biliary leaks following liver transplantation. Endoscopy 2011; 43: 512-517

Bibliography

DOI http://dx.doi.org/

10.1055/s-0033-1344995

Endoscopy 2013; 45: E354-E355

(c) Georg Thieme Verlag KG

Stuttgart · New York

ISSN 0013-726X

\section{Corresponding author}

\section{Arnaud Lemmers, MD, PhD}

Department of Gastroenterology,

Hepatopancreatology, and Digestive Oncology Erasme Hospital

Université Libre de Bruxelles (ULB)

Route de Lennik, 808

1070 Brussels

Belgium

Fax: +32-2-5554697

Arnaud.lemmers@erasme.ulb.ac.be 